\title{
Bmp6 Regulates Retinal Iron Homeostasis and Has Altered Expression in Age-Related Macular Degeneration
}

\author{
Majda Hadziahmetovic, ${ }^{*}$ Ying Song, ${ }^{*}$ \\ Natalie Wolkow, ${ }^{*}$ Jared lacovelli, ${ }^{*}$ Leon Kautz, ${ }^{\text {t† }}$ \\ Marie-Paule Roth, ${ }^{\ddagger \ddagger}$ and Joshua L. Dunaief* \\ From the F.M. Kirby Center for Molecular Ophthalmology,* Scheie \\ Eye Institute, University of Pennsylvania, Philadelphia, \\ Pennsylvania; and Inserm, U563, ${ }^{\dagger}$ and the Center for \\ Physiopathology of Toulouse Purpan, ${ }^{\ddagger}$ University of Toulouse- \\ University Paul Sabatier (UPS), Toulouse, France
}

Iron-induced oxidative stress causes hereditary macular degeneration in patients with aceruloplasminemia. Similarly, retinal iron accumulation in age-related macular degeneration (AMD) may exacerbate the disease. The cause of retinal iron accumulation in AMD is poorly understood. Given that bone morphogenetic protein $6(\mathrm{Bmp} 6)$ is a major regulator of systemic iron, we examined the role of $B m p 6$ in retinal iron regulation and in AMD pathogenesis. Bmp6 was detected in the retinal pigment epithelium (RPE), a major site of pathology in AMD. In cultured RPE cells, Bmp6 was down-regulated by oxidative stress and upregulated by iron. Intraocular $B m p 6$ protein injection in mice up-regulated retinal hepcidin, an iron regulatory hormone, and altered retinal labile iron levels. $B m p 6^{-/-}$mice had age-dependent retinal iron accumulation and degeneration. Postmortem RPE from patients with early AMD exhibited decreased Bmp6 levels. Because oxidative stress is associated with AMD pathogenesis and down-regulates Bmp6 in cultured RPE cells, the diminished Bmp6 levels observed in RPE cells in early AMD may contribute to iron build-up in AMD. This may in turn propagate a vicious cycle of oxidative stress and iron accumulation, exacerbating AMD and other diseases with hereditary or acquired iron excess. (Am J Pathol 2011, 179:335-348; DOI: 10.1016/j.ajpath.2011.03.033)

Tight iron regulation is crucial for health. Disorders of iron metabolism are among the most common diseases, and their clinical manifestations range from iron deficiency anemia to iron overload toxicity in hereditary hemochromatosis. Iron overload has been implicated in age-related neurodegenerative diseases, including Parkinson's ${ }^{1,2}$ and Alzheimer's diseases. ${ }^{3}$ Iron accumulates in many tissues with age, ${ }^{4}$ potentially exacerbating agerelated diseases by inducing oxidative stress. ${ }^{5-7}$ As in other organs, disturbed iron homeostasis in the eye leads to severe damage and dysfunction. Patients lacking the ferroxidase ceruloplasmin as a result of the autosomal recessive disorder aceruloplasminemia have an earlyonset macular degeneration with elevated retinal iron levels. ${ }^{8-10}$ Age-related macular degeneration (AMD), a multifactorial disease, ${ }^{11}$ may also be exacerbated by iron toxicity; there are higher iron levels in AMD retinas, compared with age-matched controls. ${ }^{12}$ The reasons for iron accumulation in AMD and mechanisms regulating retinal iron levels are incompletely understood.

Many of the genes that regulate iron on the systemic level have been identified over the past decade. Most of these genes are expressed in the retina and play a role in local iron regulation. ${ }^{13}$ To better understand iron homeostasis in the retina, we have previously studied doubleknockout mice deficient in both ceruloplasmin and its homolog hephaestin. These double-knockout mice have an age-dependent retinal iron accumulation consistent with a role for ceruloplasmin and hephaestin in retinal iron export. ${ }^{14,15}$ As a result of the iron accumulation, the mice develop a retinal degeneration that shares some features of AMD, including photoreceptor and retinal pigment epithelium (RPE) death, RPE hypertrophy, autofluorescence, and subretinal neovascularization. The degeneration can be prevented by administration of the oral iron chelator deferiprone. ${ }^{16}$

Supported by the NIH (R01EY015240 to J.L.D.), the American Health Assistance Foundation, the Pennsylvania Lions Eye Research Foundation, the F.M. Kirby Foundation, and the Paul and Evanina Bell Mackall Foundation Trust.

Accepted for publication March 29, 2011.

Address reprint requests to Joshua L. Dunaief, M.D., Ph.D., 305 Stellar Chance Labs, 422 Curie Blvd., Philadelphia, PA 19104. E-mail: jdunaief@upenn.edu. 
To further elucidate the mechanisms of retinal iron regulation, we studied mice lacking hepcidin $\left(\mathrm{Hepc}^{-1-}\right) .^{17}$ Hepcidin (Hepc) is a peptide hormone that regulates systemic iron by preventing iron export from enterocytes and macrophages by triggering degradation of the iron exporter protein ferroportin (Fpn). ${ }^{18}$ Because Hepc and Fpn are expressed within the retina, ${ }^{19,20}$ Hepc may be used locally for regulation of retinal iron homeostasis. Similar to the double-knockout mice, Hepc1 ${ }^{-1-}$ mice have an age-dependent iron accumulation followed by retinal degeneration. The absence of Hepc likely permits increased iron uptake into the neurosensory retina from retinal vasculature through $\mathrm{Fpn}$, which localizes to the vascular endothelium and exports iron from the abluminal side of these cells. ${ }^{17}$

Recent studies show that Hepc expression is regulated in part by the bone morphogenetic protein (Bmp) signaling pathway. ${ }^{21-23}$ These proteins are members of the tumor growth factor $\beta$ (TGF- $\beta$ ) superfamily. ${ }^{24}$ Mouse knockout experiments indicate that Bmp6 is critical for systemic iron homeostasis. ${ }^{25} \mathrm{Bmp6}^{-/-}$mice have depressed hepatic Hepc expression and iron overload in liver and other tissues. Like other members of this family, Bmp6 activates a tetrameric receptor complex consisting of two type I and two type II serine-threonine kinase receptors. Although there are three different proteins that can serve as type I receptors and three that can serve as type II receptors, Bmp6 preferentially activates a complex consisting of the type I receptor Acvr1A and the type II receptor BMPR2, ${ }^{26}$ and also the coreceptor hemojuvelin, which is expressed in the retina. ${ }^{13}$ Receptor activation induces phosphorylation of Smad proteins (Smad1, Smad5, and Smad8), which then form a complex with Smad4 and translocate to the nucleus to regulate transcription of target genes, including Hepc and Id1. ${ }^{24}$ In addition to their role in iron homeostasis through regulation of Hepc expression, bone morphogenetic proteins have diverse roles in many other physiological and pathological processes, in part through Id1 regulation. ${ }^{27-29}$ The Id proteins (inhibitors of DNA binding) have been implicated in regulating a variety of cellular processes, including cellular growth, senescence, differentiation, apoptosis, angiogenesis, and neoplastic transformation. ${ }^{30}$ The bone morphogenetic proteins are expressed widely in the embryonic nervous system, in many regions of the adult brain, and in mature human retinal neurons. $^{31,32}$ Bmp4 up-regulation has been implicated in oxidative-stress-induced RPE cell senescence in AMD. ${ }^{33}$

Because Hepc plays an important role in retinal iron homeostasis, and because Bmp6 is crucial for regulation of systemic iron homeostasis through $\mathrm{Hepc}$, in the present study we tested the role of Bmp6 within the retina. We studied retinas from Bmp6-deficent mice $\left(B m p 6^{-/-}\right)$, tested the effect of intraocular Bmp6 injection on retinal Hepc expression and retinal iron homeostasis, and assessed the effects of iron and oxidative stress on Bmp6 production in cultured RPE cells. To determine whether the oxidative stress that occurs in AMD $^{34-36}$ might cause Bmp6 dysregulation, we tested Bmp6 levels in postmortem AMD eyes.

\section{Materials and Methods}

\section{Animals}

Bmp6 knockout mice (Bmp6 $6^{\text {1Rob }}$ ) on a CD1 background were generated as described previously. ${ }^{37} 116^{-1-}$ (B6.129S2-IL $6^{\text {tm1Kopf } / J) ~ a n d ~ B A L B / C J ~ m i c e ~ w e r e ~ o b t a i n e d ~}$ from the Jackson Laboratory (Bar Harbor, ME). Hepc1 knockout mice $\left(\mathrm{Hepc}^{-/-}\right)$on a C57BL/6 background were generated as described previously. ${ }^{38}$ All procedures were in accordance with the European Convention for the Protection of Vertebrate Animals Used for Experimental and Other Scientific Purposes and were approved by the Institutional Animal Care and Use Committee of the University of Pennsylvania. The eyes were enucleated immediately after death and were fixed overnight in either $2 \%$ paraformaldehyde and $2 \%$ glutaraldehyde for histochemical iron detection and morphological analysis or in $4 \%$ paraformaldehyde for immunofluorescence.

\section{Cell Culture}

The spontaneously immortalized human RPE cell line ARPE-19 (ATCC, Manassas, VA) was cultured until confluent in 12-well Falcon plates (BD Falcon, Franklin Lakes, $\mathrm{NJ}$ ) in 1:1 Dulbecco's modified Eagle's medium/F12, 20 $\mu \mathrm{mol} / \mathrm{L}$ L-glutamine (Invitrogen, Carlsbad, CA), supplemented with heat-inactivated $10 \%$ fetal bovine serum (HyClone, Logan, UT) and 1\% penicillin/streptomycin. The cells were grown in $5 \% \mathrm{CO}_{2}$ at $37^{\circ} \mathrm{C}$. To evaluate the effect of exogenous iron on $\mathrm{Bmp} 6$ expression, confluent cells were treated with $75 \mu \mathrm{mol} / \mathrm{L} \mathrm{H}_{2} \mathrm{O}_{2}$ for 16 hours, or with $250 \mu \mathrm{mol} / \mathrm{L}$ ferric ammonium citrate (FAC) for 16 hours or 4 days. Also, to evaluate the effect of Bmp6 on hepcidin expression in ARPE-19, confluent cells were treated with $3 \mathrm{nmol} / \mathrm{L}$ Bmp6 for 16 hours. RNA isolation was performed using an RNeasy mini kit (Qiagen, Valencia, CA) according to the manufacturer's protocol. The RNA was quantified with a spectrophotometer and stored at $-80^{\circ} \mathrm{C}$. cDNA was synthesized using TaqMan reverse transcription reagents (Applied Biosystems, Carlsbad, $\mathrm{CA}$ ) according to the manufacturer's protocol. TaqMan gene expression assays were obtained from Applied Biosystems and were used for PCR analysis, as described below.

\section{Histochemical Iron Detection by Perls' Staining and Morphological Analysis}

After several days of fixation in $2 \%$ paraformaldehyde and $2 \%$ glutaraldehyde, eyecups were made by removing the anterior segment. The tissues were then dehydrated in ethanol and infiltrated overnight in embedding solution (JB4 Solution A; Polysciences, Warrington, PA). The next day, the eyecups were embedded in plastic (JB4; Polysciences). Sections were cut at 3- $\mu$ m thickness and treated with either Perls' stain for histochemical iron detection, as described previously, ${ }^{14,15}$ or with Toluidine Blue stain for standard histology. Stained sections were photographed using a Nikon TE-300 microscope. 


\section{Spectral Analysis of Tissue Autofluorescence}

Cryosections (10 $\mu \mathrm{m})$ were mounted with fluorescence mounting medium (KPL, Gaithersburg, MD) and coverslipped. Sample autofluorescence was excited with the 488-nm argon laser of a Zeiss LSM-510 confocal microscope running in lambda scan mode, and emission spectra were acquired from 500 to $714 \mathrm{~nm}$. Data analysis was performed using LSM image browser version 4.0 software.

\section{Quantitative Iron Detection}

Eyes from $\mathrm{Bmp6}^{-1-}$ and age-matched wild-type mice were fixed in $4 \%$ paraformaldehyde. Eyecups were made by removing the anterior segment. The ciliary body was removed with a curved scalpel blade, and the neurosensory retina was detached from the underlying RPE/choroid tissue. Samples of the neurosensory retina and RPE/ choroid (with sclera) were placed in separate tubes and allowed to dry at room temperature. Total nonheme iron was quantified using the bathophenanthroline sulfate (BPS) spectrophotometric protocol described by Torrance and Bothwell. ${ }^{39}$ Because the small mass of tissue (approximate weight of the mouse retina and RPE/choroids is $5 \mathrm{mg}$ each) led to reduced measurement accuracy, the tissue mass was not taken into consideration when calculating total nonheme iron using the BPS spectrophotometric protocol. Instead, the total nonheme iron is reported per retina or per RPE/choroid, as we have done previously. ${ }^{17}$ Dried tissue was digested overnight at $65^{\circ} \mathrm{C}$ in acid digest solution $(0.1 \%$ trichloroacetic acid and $0.03 \mathrm{~mol} / \mathrm{L} \mathrm{HCl}$ ). After digestion, samples were centrifuged, and the supernatant $(20 \mu \mathrm{L})$ was added to $1 \mathrm{~mL}$ of chromogen reagent $(2.25 \mathrm{~mol} / \mathrm{L}$ sodium acetate pretreated with Chelex 100 (Bio-Rad, Hercules, CA), 0.01\% BPS, and $0.1 \%$ thioglycolic acid). The absorbances were read at $535 \mathrm{~nm}$. Iron levels were calculated by comparing absorbances of tissue-chromogen samples to serial dilutions of iron standard (Sigma-Aldrich, St Louis, MO).

\section{Immunolabeling}

Mouse globes fixed in 4\% paraformaldehyde were rinsed in PBS and the eyecups were dissected. The eyecups were cryoprotected in 30\% sucrose overnight, then embedded in optimal cutting temperature compound (Tissue-Tek; Sakura Finetek, Torrance, CA). Immunofluorescence was performed on sections $10 \mu \mathrm{m}$ thick, as described previously. ${ }^{40}$ Primary antibodies were rabbit anti-light ferritin (F17) at 1:2500 dilution (the generous gift of Paolo Santambrogio and Paolo Arosio, Istituto di Ricovero e Cura a Carattere Scientifico, Milan, and Università degli Studi di Brescia, Brescia, Italy respectively), rabbit anti-TfR at 1:80 dilution (Santa Cruz Biotechnology, Santa Cruz, CA), and mouse anti-Bmp6 at 1:100 dilution (Abcam, Cambridge, MA). Primary antibody reactivity was detected using Cy3 fluorophore conjugated secondary antibodies (Jackson ImmunoResearch Laboratories, West Grove, PA). Rabbit anti-Cralbp antibodies at 1: 250 dilution were used for primary Müller cell culture (the generous gift of John Saari, University of Washington, Seattle). Control sections were treated identically, except that primary antibody was omitted. Sections were analyzed by fluorescence microscopy with identical exposure parameters using a Nikon TE300 microscope with ImagePro Plus version 6.1 (Media Cybernetics Inc., Bethesda, MD) software. Quantification of immunoreactivity was performed by measuring the mean pixel intensity within the RPE and neurosensory retina of each photomicrograph.

Cryosections from human $\operatorname{AMD}(n=7)$ and agematched control $(n=5)$ were obtained and immunostained as described previously. ${ }^{40}$ Sections were bleached to enable visualization of the immunostaining reaction product within the RPE. Bleaching was performed using potassium permanganate for 2 minutes and oxalic acid for 27 seconds (Polysciences, Warrington, PA), followed by immunostaining with mouse anti-Bmp6 at 1:500 dilution (Alpha Diagnostic International, San Antonio, TX), and by anti-mouse secondary antibody (Vectastain ABC-AP, followed by BCIP/ NBT alkaline phosphatase substrate; Vector Laboratories, Burlingame, CA).

\section{Intravitreal and Subretinal Injections}

The intravitreal and subretinal injections were delivered through $10-\mu \mathrm{L}$ Hamilton microsyringes (Hamilton, Reno, NV) with 32-gauge needles. Localization of subretinal injections was confirmed by presence of the retinal detachment by optical coherence tomography (Bioptigen, Research Triangle Park, NC). The right eye of each animal was injected with $1 \mu \mathrm{L}$ of PBS and served as a control; the left eye was injected with $1 \mu \mathrm{L}$ of $50 \mathrm{nmol} / \mathrm{L}$ human Bmp6 (R\&D Systems, Minneapolis, MN). Mice were euthanized 6 and 12 hours after the injections, and the neurosensory retinas, combined RPE/choroid or isolated RPE (as indicated), were collected.

\section{Light Damage Experiment}

Male BALB/cJ mice $(n=4)$, were exposed to 10,000 lux cool white fluorescent light for 18 hours, as described previously, ${ }^{41}$ and the control group $(n=4)$ was kept on a regular 12-hour light-dark cycle. Mice were sacrificed 4 hours after photic injury ended, and the neurosensory retina and isolated RPE were collected for mRNA quantification.

\section{RPE Isolation}

Purified RPE cells were isolated by removing the anterior segment (cornea, iris, and lens) from enucleated mouse eyes after a two-step digestion. Briefly, the eyes were incubated at $37^{\circ} \mathrm{C}$ for 40 minutes in $2 \% \mathrm{w} / \mathrm{v}$ dispase in $1 \times$ Hanks' balanced salt solution with $\mathrm{Ca}^{2+}$ and $\mathrm{Mg}^{2+}$ $(\mathrm{HBSS}+)$ (Invitrogen). After digestion with dispase, slits were made in the cornea with a scalpel blade and the eyes were incubated for additional 10 minutes in 1 $\mathrm{mg} / \mathrm{mL}$ hyaluronidase in Hanks' balanced salt solution without $\mathrm{Ca}^{2+}$ and $\mathrm{Mg}^{2+}$ (HBSS-). After two washes in $\mathrm{HBSS}+$, the anterior segment was removed and the eyecup was placed in HBSS-, where the neurosensory ret- 
ina was removed. The RPE cells were gently brushed from the eyecup in fresh HBSS -, collected, and pelleted at $1200 \times g$ for 15 minutes. The supernatant was removed and the cells were stored at $-80^{\circ} \mathrm{C}$ until the RNA isolation was performed with an RNeasy micro kit (Qiagen) according to the manufacturer's protocol.

\section{Quantitative Real-Time PCR}

Neurosensory retina and RPE/choroid samples obtained from $B m p 6^{-\prime-}, 116^{-1-}$, and wild-type mice were analyzed using quantitative real-time PCR for gene expression. RNA isolation was performed with an RNeasy mini kit (Qiagen) according to the manufacturer's protocol. The RNA was quantified with a spectrophotometer and stored at $-80^{\circ} \mathrm{C}$. cDNA was synthesized using TaqMan reverse transcription reagents (Applied Biosystems) according to the manufacturer's protocol. TaqMan gene expression assays were obtained from Applied Biosystems and used for PCR analysis. Probes used were hepcidin antimicrobial peptide (Hepc1, Mm00519025_m1 and Hs00221783_m1), bone morphogenetic protein 6 (Bmp6, Mm00432095_m1 and Hs01099594_m1), bone morphogenetic protein receptor type II (Bmpr2, Mm01254942_m1), Activin A receptor type I (Acvr1, Mm01331069_m1), transferrin receptor (Tfr, Mm00441941_m1), inhibitor of DNA binding 1 (Id1, Mm00775963_g1), heme oxygenase (Hmox1, Mm00516005_m1 and Hs01110250_m1), bone morphogenetic protein 2 (Bmp2, Mm01340178_m1), bone morphogenetic protein 4 (Bmp4, Mm0043208_m1), bone morphogenetic protein 7 (Bmp7, Mm00432102_m1), and bone morphogenetic protein 9 (Bmp9, Mm00807340_m1). Eukaryotic 18S rRNA (Hs99999901_s1) served as an internal control, because of its constant expression level across the studied sample sets. Real-time TaqMan RT-PCR (Applied Biosystems) was performed on an ABI Prism 7500 sequence detection system using the $\Delta \Delta \mathrm{C}_{\mathrm{T}}$ method, which provides normalized expression values. The amount of target mRNA was compared among the groups of interest. All reactions were performed in biological (three mice) and technical (three real-time PCR replicates per mouse) triplicates.

\section{ELISA}

Enzyme-linked immunosorbent assay (ELISA) was performed using a human Bmp6 DuoSet ELISA development system (R\&D Systems Minneapolis, MN) according to the manufacturer's protocol. Microtiter plates (Immuno 96-microwell solid plates, Maxisorp; Thermo Fisher Scientific, Rochester, NY) were coated with $4 \mu \mathrm{g} / \mathrm{mL}$ of capture antibodies (mouse anti-human Bmp6) in PBS overnight at room temperature. After four washes with wash buffer $(0.05 \%$ Tween 20 in PBS), the plates were blocked by adding reagent diluent (1\% BSA in PBS) for 1 hour at room temperature. After four washes with wash buffer, samples or standards (100 $\mu \mathrm{L}$ ) in reagent diluent were added, and the plates were incubated for 2 hours at room temperature. After an additional four washes, the plates were incubated with $100 \mu \mathrm{L}$ of detection antibodies (biotinylated goat antihuman Bmp6) for 2 hours at room temperature. After a washing step, the plates were incubated for 20 minutes at room temperature with $100 \mu \mathrm{L}$ of streptavidin-horseradish peroxidase (1:200 dilution). After a final wash, $100 \mu \mathrm{L}$ of substrate solution ( $1: 1$ mixture of $\mathrm{H}_{2} \mathrm{O}_{2}$ and tetramethylbenzidine) was added to each well and the plates were incubated for 20 minutes at room temperature protected from direct light. Colorimetric reaction was stopped by adding 50 $\mu \mathrm{L}$ of $2 \mathrm{~N} \mathrm{H}_{2} \mathrm{SO}_{4}$. The optical density of each well was determined immediately, using a microplate reader set to $450 \mathrm{~nm}$; the correction for optical imperfections in the plate was done by subtracting wavelength readings at $570 \mathrm{~nm}$ from those at $450 \mathrm{~nm}$.

\section{Primary Müller Cell Culture}

Primary cultures of retinal Müller cells were established from retinas of 9-day-old C57BL/6 mice by a method based on that of Hicks and Courtois. ${ }^{42}$ Briefly, the globes were removed immediately after the mice were sacrificed and incubated in Dulbecco's modified Eagle's medium and $1 \% \mathrm{w} / \mathrm{v}$ penicillin/streptomycin overnight at room temperature in the dark. The next morning, after a rinse in $70 \%$ ethanol and PBS, the globes were incubated in $2 \%$ w/v dispase (Invitrogen) for 45 minutes at $37^{\circ} \mathrm{C}$. After three washes in D10 (Dulbecco's modified Eagle's medium, $10 \% \mathrm{w} / \mathrm{v}$ fetal bovine serum, $1 \% \mathrm{w} / \mathrm{v}$ penicillin/ streptomycin), the eyecups were made by removing the anterior segment of the eye and the neurosensory retina was separated from underlying RPE/choroid and sclera. The retinas were transferred to fresh D10 solution, cut into $1-\mathrm{mm}^{2}$ pieces using a curved scalpel, and transferred to a T25 flask in $1 \mathrm{~mL}$ total volume. The next day, the old medium was replaced with fresh D10 and loose retinas were discarded. Isolated cells were detectable within 3 days. When substantial cell growth was observed, the cultures were vigorously washed with medium until only adherent cell population remained. When the cultures were near confluent, the cells were seeded into 6-well plates and the culture medium was changed every second day. When confluent, the cells were treated in triplicate with either $3 \mathrm{nmol} / \mathrm{L} \mathrm{Bmp6}$ in D10 or with D10 only (controls) for 6 hours. After the treatment, the cells were rinsed with PBS, and RNA isolation was performed with an RNeasy mini kit (Qiagen) according to the manufacturer's protocol. The RNA was quantified and stored at $-80^{\circ} \mathrm{C}$. cDNA was synthesized using TaqMan reverse transcription reagents (Applied Biosystems) according to the manufacturer's protocol.

\section{Western Analysis}

The eyes from healthy donors and AMD patients were obtained post mortem through the Alabama Eye Bank in accordance with the Declaration of Helsinki. Informed consent for donation and access to ophthalmic histories was obtained from the eye donor's next of kin. The eyes were dissected by separating neurosensory retina from the underlying RPE/choroid and sclera. Dissected retinas were frozen in liquid nitrogen and stored at $-80^{\circ} \mathrm{C}$. For Western blot analysis after homogenization, the retinas were lysed in radioimmunoprecipitation assay buffer and 

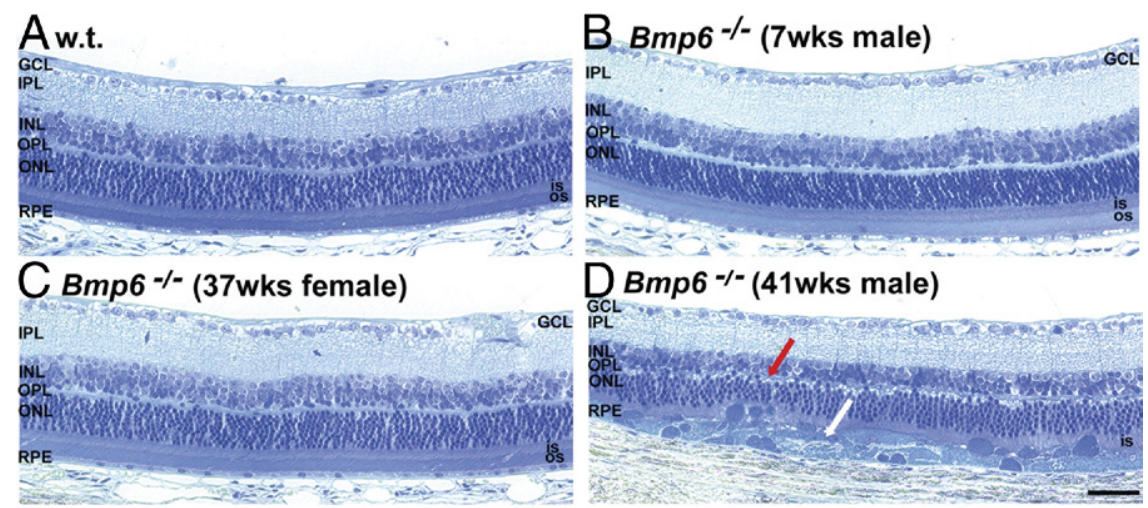
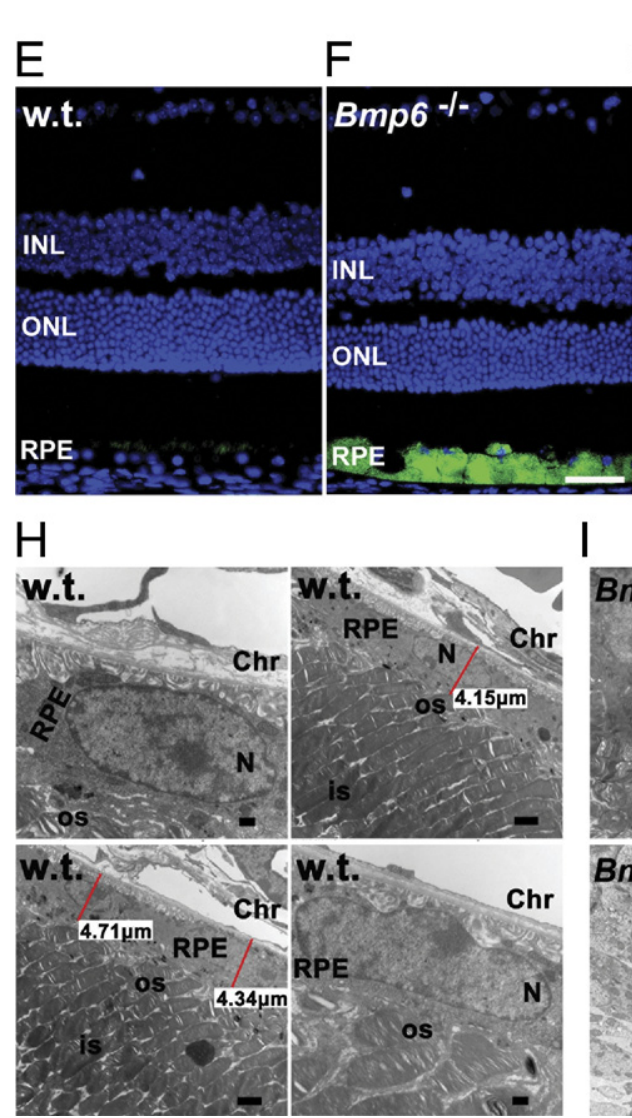

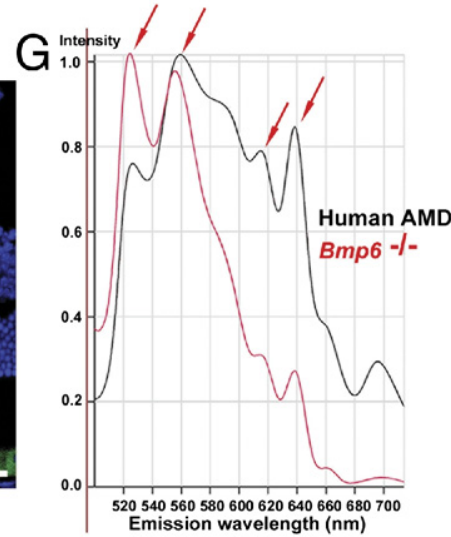

I

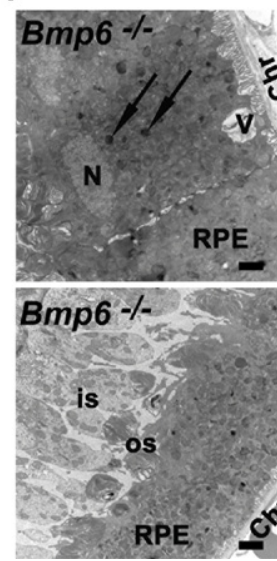

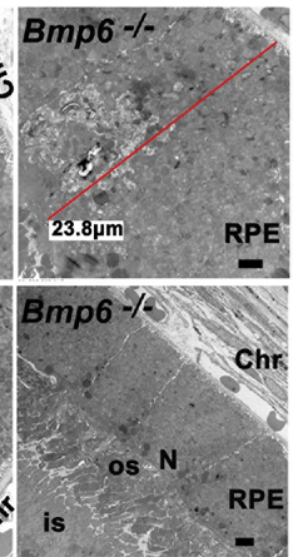

Figure 1. $B m p 6^{-1}$ mice had retinal degeneration and accumulation of lipofuscin-like material in hypertrophic RPE cells. A-D: Bright-field photomicrographs of plastic sections show that, relative to 38-week-old wild-type mice (A), the agematched male $B m p \sigma^{-1-}$ mice $(n=5 ; \mathbf{D})$ had RPE hypertrophy (white arrow) with degeneration of overlying photoreceptor inner and outer segments and thinning of the outer nuclear layer (red arrow). The age-matched female $B m p \sigma^{-}$ mice $(n=3)$ showed no retinal degeneration (C), similar to younger ( 7 weeks old; $n=3$ ) male $B m p 6^{-1-}$ mice $(\mathbf{B})$. E and $\mathbf{F}$ : Fluorescence photomicrographs show green autofluorescent lipofuscin-like material in 10-month-old male $B m p 6^{-1-} \mathrm{RPE}(\mathbf{F})$, but minimal autofluorescence in the RPE of the age-matched control (E). Nuclei were stained with DAPI (blue). G: Spectral analysis of relative autofluorescence emission intensities (with $488 \mathrm{~nm}$ excitation), revealed several similar emission peaks (arrows) among hypertrophic RPE cells from $B m p 6^{-/-}$mice compared with RPE from the postmortem retina of a patient with AMD. H: Electron micrographs of 10month-old wild-type mice show normal-appearing RPE cells, with healthy overlying photoreceptor inner and outer segments. I: Age-matched male $B m p \sigma^{-1-}$ contained rectangular RPE cells that were almost $25 \mu \mathrm{m}$ tall (versus $5 \mu \mathrm{m}$ in wild-type), severely hypertrophic, with apically displaced nuclei, cytoplasm filled with vesicles (arrows), and vacuolization (V). Overlying photoreceptor outer segments were severely degenerated. Chr, choroid; GCL, ganglion cell layer INL, inner nuclear layer; IPL, inner plexiform layer; IS, photoreceptor inner segment; N, nucleus; ONL, outer nuclear layer; OPL, outer plexiform layer; OS, photoreceptor outer segment RPE, retinal pigment epithelium; V, vacuole. Scale bars: $50 \mu \mathrm{m}(\mathbf{F}) ; 5 \mu \mathrm{m}$ (I, lower right); 2 $\mu \mathrm{m}$ (H, upper right and lower left; I, upper row and lower left); $500 \mathrm{~nm}$ (H, upper left and lower right) protein was quantified using a BCA protein assay kit (Thermo Scientific, Rockford, IL). Twenty micrograms total protein was used per lane. Recombinant human Bmp6 protein (Alpha Diagnostic International) was used as a positive control according to the manufacturer's recommendations. The samples were incubated in loading buffer for 10 minutes at $70^{\circ} \mathrm{C}$. Protein lysates were separated on a $4 \%$ to $12 \%$ SDS-PAGE gel and transferred to nitrocellulose membrane. Blocking was achieved by incubation in Tris-buffered saline containing 5\% milk and $0.1 \%$ Tween 20. Membranes were incubated overnight at $4^{\circ} \mathrm{C}$ with mouse monoclonal anti-human Bmp6 antibodies at 1:1000 dilution (Alpha Diagnostic International). After washes, membranes were incubated with anti-mouse IgG at 1:5000 dilution (GE Healthcare, Piscataway, NJ) and developed using ECL Plus enhanced chemilumines- cence reagent (GE Healthcare, Chalfont St. Giles, UK). Anti- $\alpha$-tubulin antibody (Sigma-Aldrich) was used as loading control. Images were acquired using a Typhoon 9400 variable mode imager (GE Healthcare, UK) and densitometry analysis was performed using ImageQuant TL software version 2005 (GE Healthcare).

\section{Statistical Analysis}

The mean and the standard error were calculated for each comparison group. The means between the groups were compared using the two-group $t$-test. A $P$ value of $<0.05$ was considered to be statistically significant. Data are reported as means \pm SEM. All statistical analysis was performed with GraphPad Prism version 5 (GraphPad Software, San Diego, CA). 
A



B
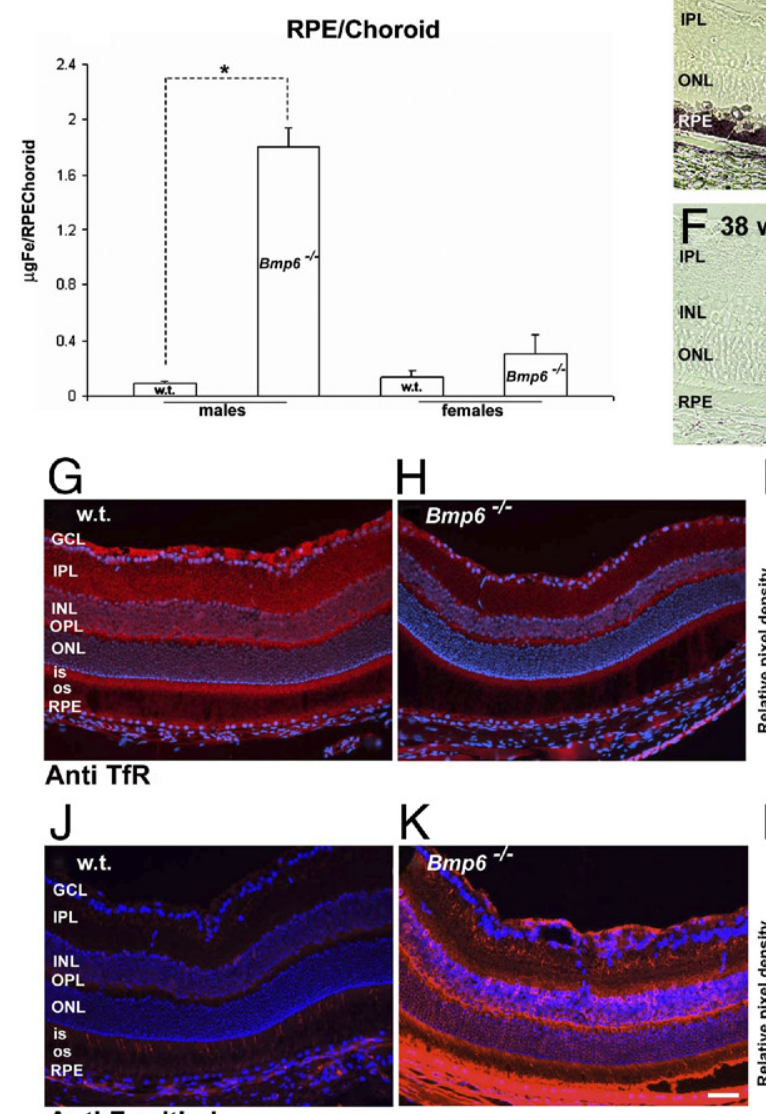

Anti Ferritin L
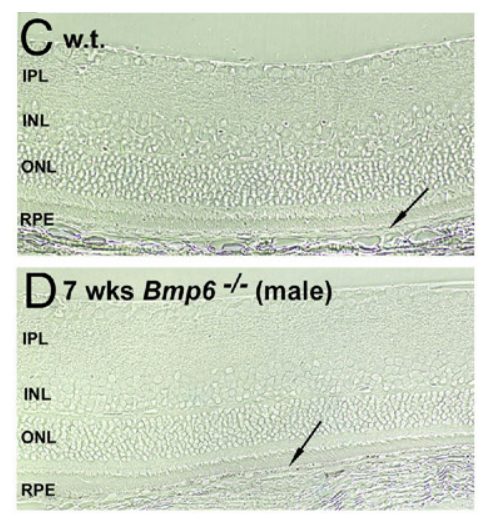

$E_{38 \text { wks Bmp6 } \% \text { (male) }}$

IPL

ONL

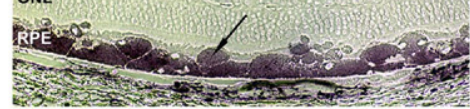

F 38 wks Bmp6\% $\%$ (female)



INL

ONL

RPE

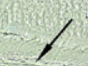

I

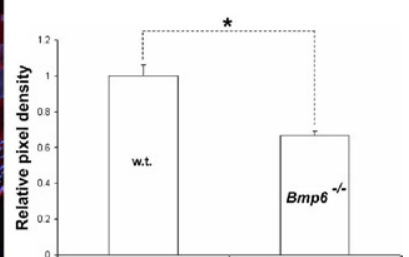

L

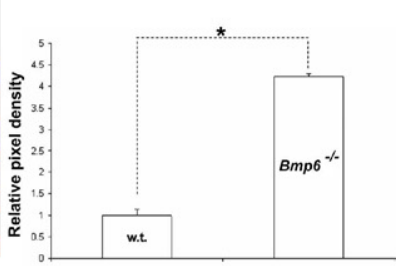

Figure 2. Retinal iron in wild-type and agematched $B m p \sigma^{-/}$mice. A and B: Total nonheme iron quantification by bathophenanthroline sulfate (BPS) in the retinas (A) and RPE/ choroid (B) of 41-week-old male and female $B m p 6^{-/-}$relative to age-matched controls. C-F: Bright-field photomicrographs of Perls' stained plastic-embedded wild-type retinas (C), 7-weekold male (D) and 38-week-old male (E) and female (F) $B m p 6^{-/-}$mouse retinas show iron accumulation in the RPE and choroid only of 38 week-old male $B m p \sigma^{-/-}$mice (arrow). G, H, J, and $\mathbf{K}$ : Fluorescence photomicrographs of retinas from 41-week-old $B m p \sigma^{-/-}$mice (H) show decreased TfR immunoreactivity (red) throughout the retina, relative to age-matched controls (G). Fluorescence photomicrographs showed stronger L-ferritin (K) immunoreactivity in $B m p 6^{-1-}$ mice retinas, compared with agematched wild-type controls (J). I and L: Immunoreactivity was quantified by measuring the mean pixel intensity within the RPE and neurosensory retina of each photomicrograph $(n=3$ for each antibody and genotype). ${ }^{*} P<0.05$. Scale bars $=50 \mu \mathrm{m}$.

\section{Results}

\section{Retinal Degeneration in Adult Bmp6 ${ }^{-1-}$ Mice}

Retinas from male $\mathrm{Bmp6}^{-/-}$mice were morphologically normal at 7 weeks (Figure 1B), but developed severe pathology at 41 weeks. Approximately $50 \%$ of the retina had massively hypertrophic and hyperplastic RPE cells, accompanied by loss of overlying photoreceptor inner and outer segments and thinning of the photoreceptor outer nuclear layer (Figure 1D). Most of these hypertrophic cells immunolabeled with RPE65, and none with CD68 (data not shown), indicating that these were RPE cells and not macrophages. Age-matched female $\mathrm{Bmp6}^{-/-}$mice (Figure 1C) had normal morphology.
Comparisons were made with age-, sex-, and strainmatched wild-type retinas (Figure 1A).

\section{Lipofuscin-Like Material in Hypertrophic RPE Cells of Bmp6 ${ }^{-1-}$ Mice}

Lipofuscin accumulation has been described in aging tissue, including the RPE. ${ }^{43}$ RPE cells that accumulate this autofluorescent pigment have diminished phagocytosis of rod outer segments and increased susceptibility to light toxicity. ${ }^{44}$ In contrast to healthy, 41-week-old wild-type retinas (Figure 1E), bright autofluorescence was detected by fluorescence microscopy in the hypertrophic RPE of agematched $\mathrm{Bmp6}^{-/-}$males (Figure 1F). Spectral analysis of 
A w.t.

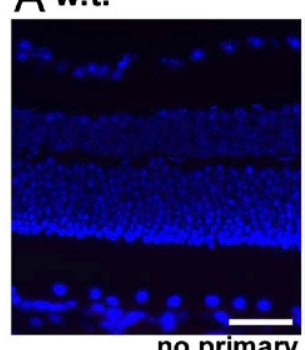

B



C

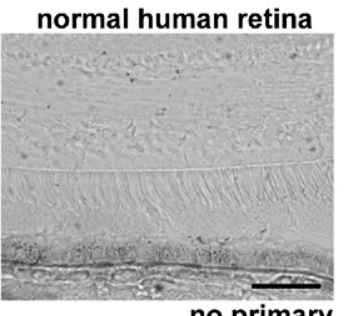

no primary
D

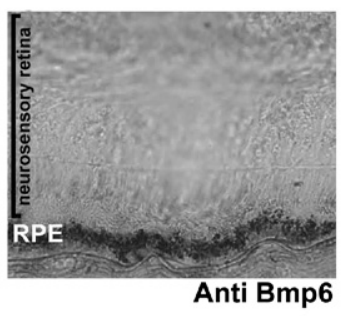

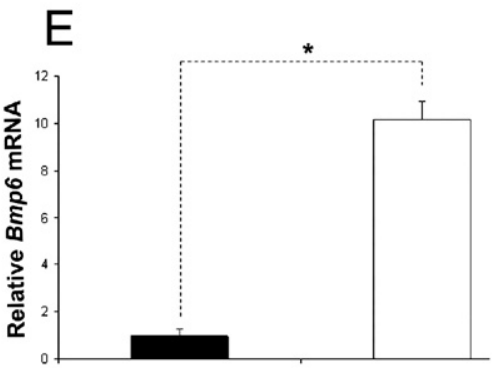
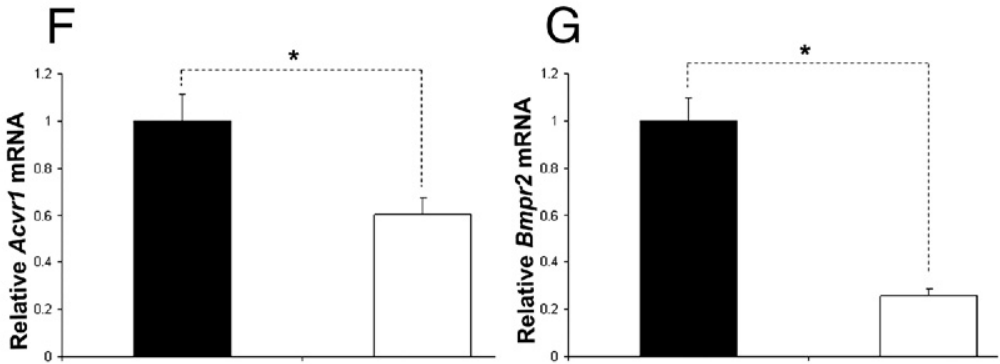

Figure 3. Localization and quantification of retinal Bmp6 and Bmp receptors. A-D: Fluorescence photomicrographs of mouse retinas with no primary antibody (A) or anti-Bmp6 (B) showed strong Bmp6 immunofluorescence (red) within the RPE, photoreceptor inner segment, outer plexiform layer, inner plexiform layer, and ganglion cell layer. The signal in the normal human retina was strongest (black immunostain) within the RPE (D) in comparison to only faint color in the RPE resulting in completely bleached melanin when the primary antibody was omitted (C). E-G: Bmp6 mRNA levels measured by real-time PCR were significantly higher (10-fold) in the isolated RPE (white bars) relative to the neurosensory retina (black bars) $(n=3$; E), whereas expression of Bmp receptors Acvr1 ( $n=3$; F) and $\operatorname{Bmpr} 2(n=3 ; \mathbf{G})$ was significantly higher in the neurosensory retina (1.66- and 3.9-fold, respectively). ${ }^{*} P<0.05$. Scale bars $=50 \mu \mathrm{m}$.

autofluorescent RPE cells from the mutant mice revealed several emission peaks similar to those of RPE cells from the postmortem eye of a patient with AMD (Figure 1G). This finding suggests that some of the lipofuscin components in $B m p 6^{-1-}$ hypertrophic RPE cells might be similar to those found in human RPE cells with AMD. Electron microscopy was used to analyze morphological changes in the mutant mice on the ultrastructural level. Relative to wild-type RPE cells (Figure $1 \mathrm{H}$ ), Bmp6 ${ }^{-/-}$mice had many enlarged, rectangular RPE cells, almost five times taller then normal (Figure 1I), with apically displaced nuclei. The cytoplasm was filled with numerous single-membrane bound vesicles, which were most likely lysosomes or endosomes, and the overlying photoreceptor outer segments were degenerated (Figure 1I).

\section{Localization and Quantification of Iron in the Bmp6 $^{-/-}$Retinas}

Quantification of total nonheme iron by BPS spectrophotometry revealed fourfold higher total iron concentration in the neurosensory retinas of 41 -week-old male $B m p 6^{-1-}$ mice (Figure 2A), relative to age-matched male controls. There was no difference in iron levels in the neurosensory retinas of female $B m p 6^{-1-}$ mice (Figure $2 \mathrm{~A}$ ) compared with ageand sex-matched controls. The RPE/choroid of male mice also had significantly higher (almost 20-fold) iron levels relative to the age- and sex-matched control group (Figure 2B). RPE/choroid results in female mice were consistent with neurosensory retina findings and showed no difference relative to wild-type controls (Figure $2 \mathrm{~B}$ ). Iron quantification results were consistent with histochemical iron detection; strong granular Perls' stain was present in the RPE of 38- week-old male $B m p 6^{-\prime-}$ mice (Figure $2 \mathrm{E}$ ), but iron was not detected in either 7-week-old male $\mathrm{Bmp}^{-/-}$mice (Figure 2D) or 38-week-old female $B m p 6^{-1-}$ mice. All comparisons were made relative to 38-week-old strain-matched wild-type mice of both sexes that showed no visible Perls' stain within the neurosensory retina or RPE (Figure 2C).

\section{Bmp6 $^{-1-}$ Eyes Have Decreased Transferrin Receptor and Increased L-Ferritin}

Transferrin receptor protein (TfR) mediates cellular iron uptake. Levels of the transferrin receptor (Tfrc) mRNA that encodes $\mathrm{TfR}$ are regulated by cytosolic labile iron levels, through the iron regulatory proteins IRP1 and IRP2, so that when labile iron levels are high, Tfro mRNA stability decreases, leading to decreased Tfrc mRNA levels. The levels of the cytosolic iron storage protein ferritin are also regulated by labile iron levels through iron regulatory proteins, but in the opposite direction: when labile iron levels are high, ferritin translation increases. ${ }^{45-47}$

Consistent with the elevated iron levels detected in $B m p 6^{-1-}$ male mice by BPS and Perls' staining, TfR immunoreactivity was decreased (Figure 2, $G$ and $H$ ). To determine whether increased iron in the mutant mouse retinas is accompanied by increased ferritin, retinas were immunolabeled with anti-L-ferritin. Immunoreactivity of L-ferritin (light ferritin) was much stronger throughout the $B m p 6^{-/-}$retinas than in agematched controls, even in areas without RPE hypertrophy (Figure 2, J and K). 


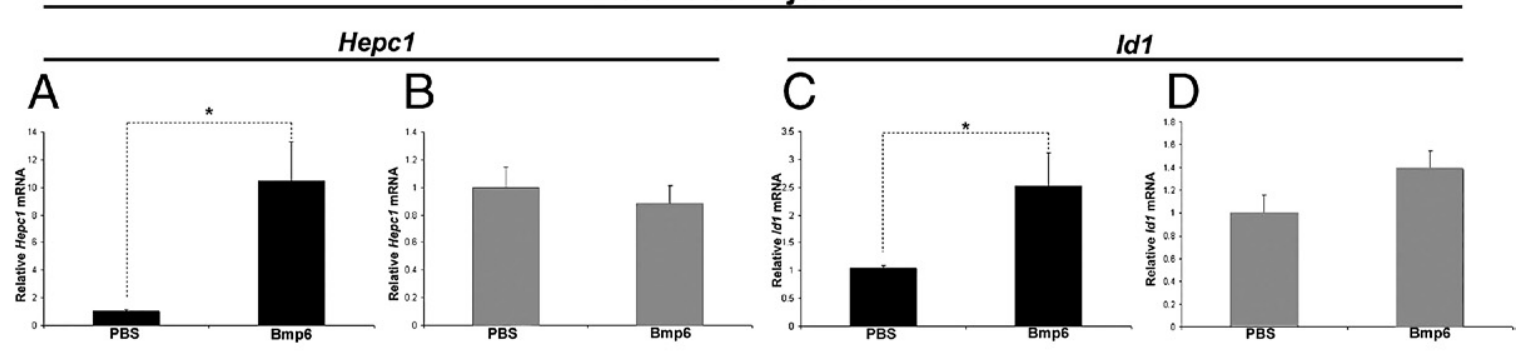

Subretinal injections
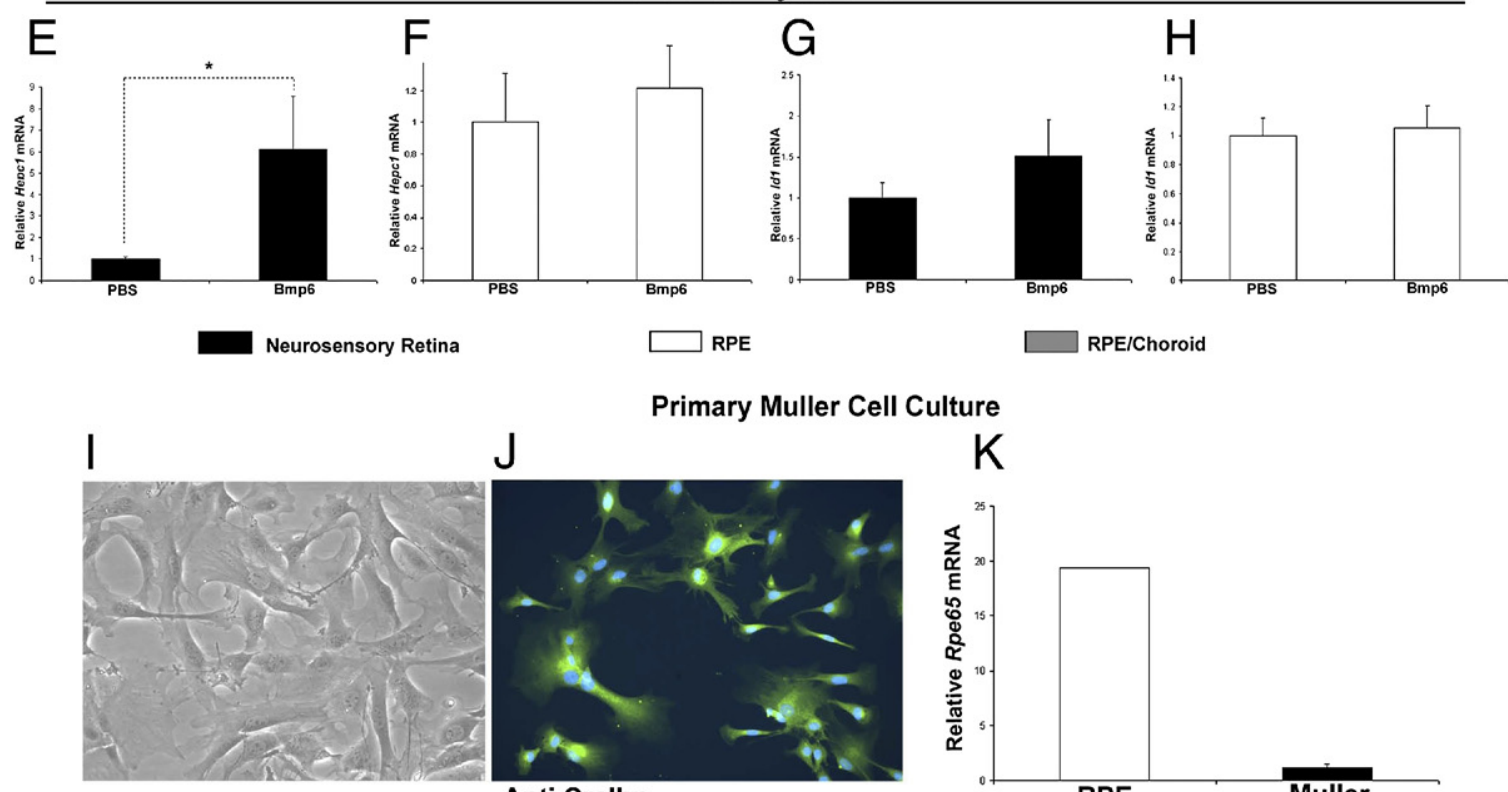

Anti Cralbp

RPE/Choroid

Primary Muller Cell Culture


Figure 4. Effect of intraocular Bmp6 injection on retinal Hepc mRNA assessed by real-time PCR. A-H: At 6 hours after intravitreal (A) and subretinal (E) injections of Bmp6 in $I l 6^{-/}$mice, neurosensory retina showed significantly higher (10- and 6-fold, respectively) levels of Hepc1 mRNA, relative to PBS-injected control eyes $(n=4$ each). B: RPE/choroid showed no difference in Hepc1 mRNA between Bmp6 injected and control eyes after intravitreal injection. F: After subretinal injection, RPE showed no difference in Hepc1 expression between Bmp6 and PBS injected eyes $(n=4$ each). At 6 hours after intravitreal injection of Bmp6, neurosensory retina showed significant increase in Id1 mRNA (2.5-fold) (C), relative to PBS-injected eye, whereas RPE/choroid showed no difference (D). No significant difference in Id1 mRNA was observed in either neurosensory retina $(\mathbf{G})$ or RPE $(\mathbf{H})$ after subretinal injections of Bmp6. I and $\mathbf{J}$ : Photomicrograph and fluorescence photomicrograph show two different wells of primary Müller cells imaged with phase contrast (I) and immunofluorescence with anti-Cralbp (J). Original magnification, $\times 400$. K: Rpe65 mRNA levels are nearly 20-fold greater in primary mouse RPE versus primary mouse Müller cells. L and M: At 6 hours after the treatment with $3 \mathrm{nmol} / \mathrm{L}$ Bmp6, treated cells had significantly higher levels of Hepc1 $(\mathbf{L})$ and Id1 $(\mathbf{M})$ mRNA, relative to untreated controls. ${ }^{*} P<0.05$

\section{Retinal Localization of Bmp6 and Bmp Receptors}

To better understand the role of the Bmp pathway in retinal iron homeostasis, we localized Bmp6 and its type I and type II receptors in the retina. Strong Bmp6 immunoreactivity was found on the apical side of the RPE in both mouse (Figure 3B, red immunofluorescence) and human retinas (Figure 3D, black immunostain). The inner segments of the photoreceptors, outer and inner plexiform, and ganglion cell layers were also immunoreactive in the mouse, but not normal human retina. Because Bmp6 is a secreted signaling molecule, we used real-time PCR to find where in the retina Bmp6 mRNA is produced. Isolated RPE cells exhibited almost 10-fold higher Bmp6 mRNA levels relative to the neurosensory retina (Figure $3 \mathrm{E}$ ). In contrast, the mRNA of the Bmp receptors Acvr1 and Bmpr2 was found at significantly higher levels in the neurosensory retina. The neuro- 


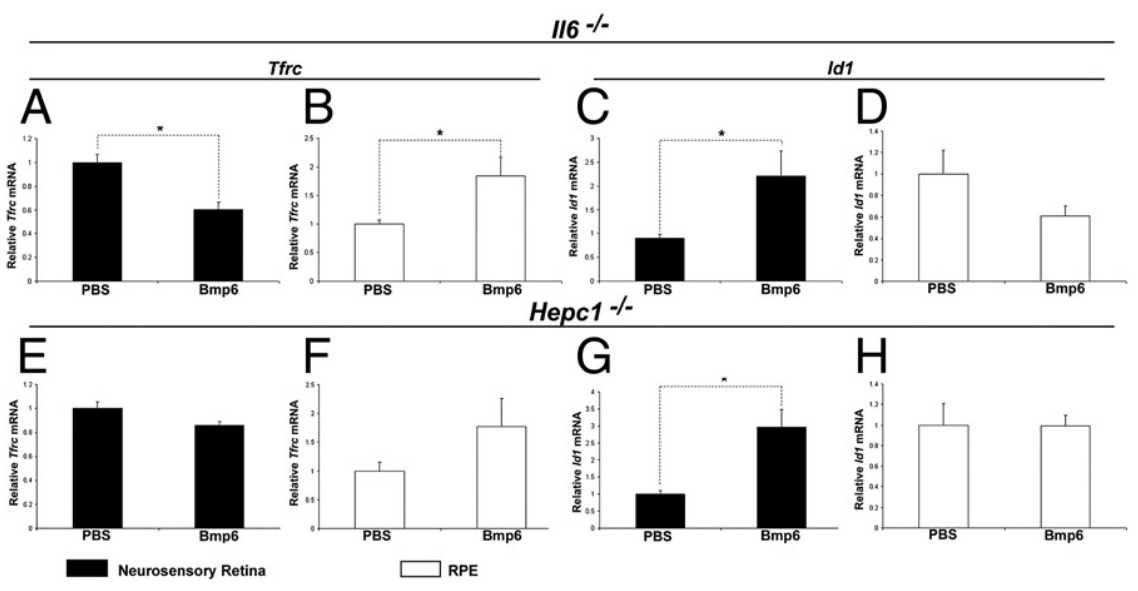

Figure 5. Effect of intravitreal Bmp6 on retinal labile iron levels assessed by real-time PCR for Tfre mRNA. At 12 hours after intravitreal injection of Bmp6 in $1 l 6^{-1-}$ mice, neurosensory retina showed significant down-regulation (1.7-fold; $\mathbf{A})$ and RPE showed significant up-regulation (1.8fold; B) of Tfrc mRNA relative to PBS injected control eyes ( $n=4$ each). Id1 was up-regulated in neurosensory retina (C), but there was no significant difference in RPE (D). In contrast, in travitreal injection of $\mathrm{Bmp} 6$ in $\mathrm{Hepc1}^{-/-}$mice had no significant change in Tfrc mRNA in either neurosensory retina $(n=3 ; \mathbf{E})$ or $\operatorname{RPE}(n=3 ; \mathbf{F})$, whereas Id1 was significantly up-regulated (almost threefold) in neurosensory retina $(\mathbf{G})$, but not in RPE $(\mathbf{H}) .{ }^{*} P<0.05$.

sensory retina may therefore be the target tissue for RPEproduced Bmp6 (Figure 3, F and G).

\section{Up-Regulation of Hepcidin in Neurosensory Retina in Response to Bmp6}

Previous research on the liver ${ }^{21,22,48}$ has shown that Hepc can be up-regulated by Bmp6. Because the neurosensory retina expresses both Hepc and the Bmp6 receptors, we next tested whether Bmp6 can up-regulate Hepc in the neurosensory retina. To accomplish this, Hepc mRNA levels were measured in the neurosensory retinas from $1 / 6^{-1-}$ mice after intravitreal and subretinal injections of Bmp6 protein. $1 / 6^{-1-}$ mice were chosen to remove the confounding influence of needle-injury-induced II6-mediated Hepc up-regulation. ${ }^{17}$ After both intravitreal and subretinal injection, Hepc was significantly up-regulated in the neurosensory retinas of Bmp6-injected eyes, relative to PBS injected controls (Figure 4, A and $\mathrm{E}$ ). In contrast, RPE/choroid (Figure 4, B and F) did not up-regulate Hepc expression. As further confirmation that the Bmp6 signaling pathway was activated, we tested whether Id1, another Bmp6-responsive gene, ${ }^{49}$ would also be up-regulated by Bmp6 in retina. There was a significant increase in Id1 mRNA levels (Figure 4C) after intravitreal injection of Bmp6, whereas no difference was observed within RPE/choroid. No significant difference was observed in Id1 message in either the neurosensory retina or the RPE subsequent to subretinal injection of Bmp6 (Figure 4, G and $\mathrm{H}$ ).

Because Müller glial cells express Hepc both in vivo and in culture, ${ }^{19}$ we tested whether Müller cells up-regulate Hepc in response to Bmp6 protein. To accomplish this, we established primary Müller cell culture as described previously. ${ }^{42}$ The purity of the culture was verified by anti-Cralbp immunolabeling and relative quantification of RPE-specific $65 \mathrm{kDa}$ protein (RPE65) mRNA. All of the cultured cells were Cralbp-positive (Figure 4J), narrowing their possible identity to Müller or RPE. The RPE65 levels were then compared by qPCR to a primary RPE culture, and found to be 20-fold higher in the RPE culture (Figure 4K), indicating only slight contamination of the culture with RPE cells. After treatment with Bmp6, the expression of both Hepc and Id1 were significantly increased in primary Müller cells (Figure 4, L and M), suggesting that Müller cells are a neurosensory retina cell type that is responsive to secreted Bmp6.

\section{Bmp6 Regulates Retinal Labile Iron}

To determine whether exogenous Bmp6 alters labile iron pools within the retina, Tfrc mRNA, the levels of which are regulated by labile iron, was quantified after intravitreal Bmp6 injections in $1 / 6^{-1-}$ mice. Significantly decreased Tfrc mRNA levels were observed within the neurosensory retinas after intravitreal Bmp6 injection (Figure 5A). This suggests an increase of labile iron pools relative to the control. In contrast to neurosensory retina, the same treatment significantly up-regulated Tfrc mRNA levels in RPE cells, suggesting a decrease in labile iron levels in the RPE cells (Figure 5B).

To determine whether Bmp6-induced alteration of labile iron pools within the retina results from Hepc upregulation, Tfrc mRNA was quantified after intravitreal injections of Bmp6 into Hepc1 ${ }^{-1-}$ mice. After the injections, no difference in Tfrc expression was observed between Bmp6-treated and control eyes in either neurosensory retina or RPE (Figure $5, E$ and $F$ ). To ensure that Bmp6 signaling occurred in $\mathrm{Hepc} 1^{-/-}$mice, we quantified Id 1 mRNA. Significant up-regulation of Id1 was found in the neurosensory retinas (Figure $5 \mathrm{G}$ ) after Bmp6 injection, as had been seen in the $1 / 6^{-1-}$ mice.

\section{Bmp6 Is Up-Regulated by Iron in Cultured RPE Cells}

To determine whether exogenous iron can affect Bmp6 production by RPE cells, the RPE cell line ARPE-19 was treated with FAC for 16 hours or 4 days. Treatment for 16 hours significantly up-regulated Bmp6 mRNA (Figure 6A) relative to untreated control cells, suggesting that iron load up-regulates Bmp6 in the RPE. Treatment with the same FAC concentration for 4 days did not up-regulate Bmp6. Because Bmp6 is a secreted protein, we tested its concentration in the cell medium after a 16-hour treatment with FAC. Untreated cells produced almost unde- 

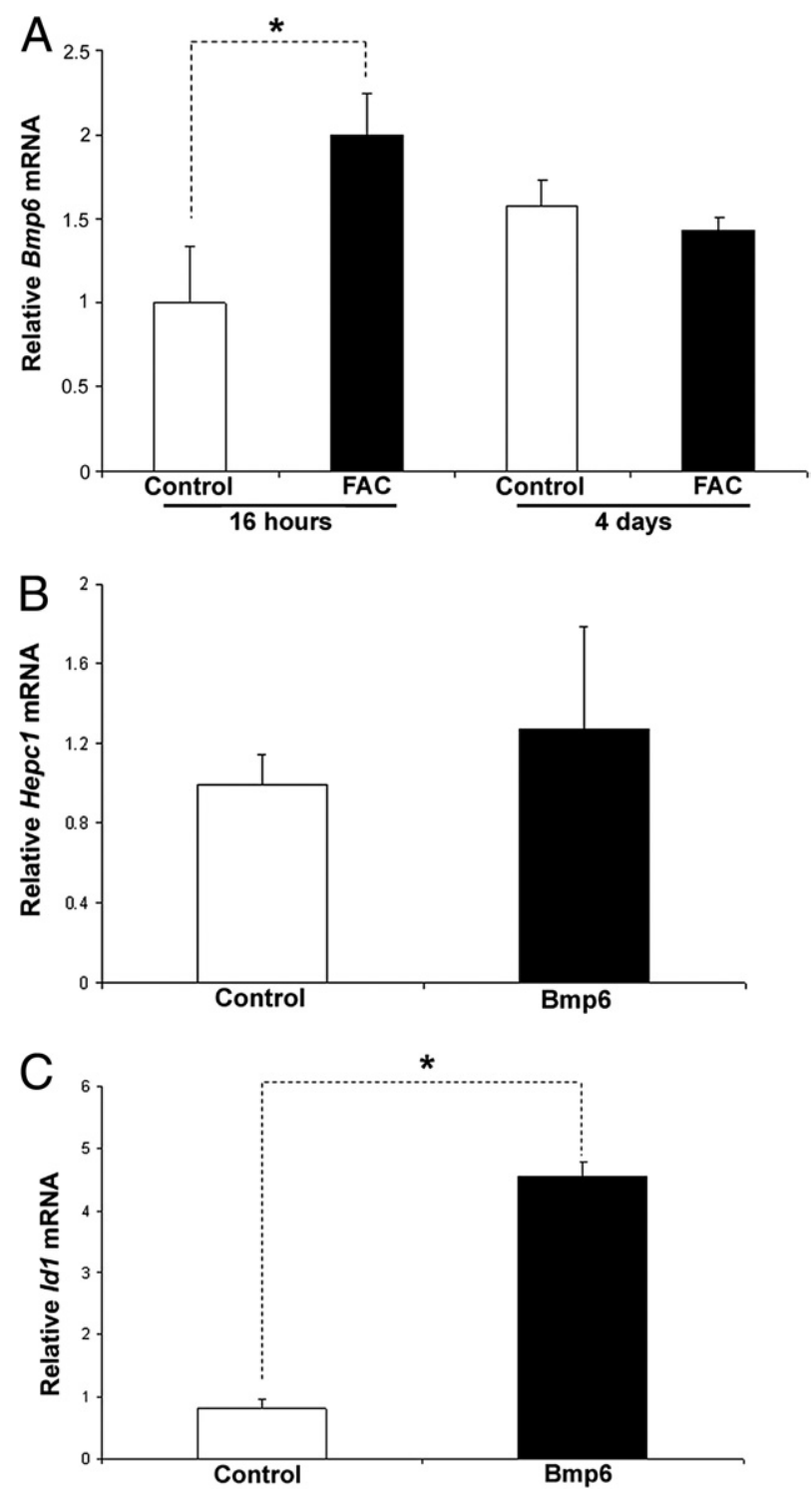

Figure 6. Effect of iron-loading on Bmp6 and Hepc1 mRNA in ARPE-19 cells assessed by real-time PCR. A: Treatment of ARPE-19 cells with $250 \mu \mathrm{mol} / \mathrm{L}$ FAC for 16 hours significantly up-regulated (1.7-fold, Bmp6 mRNA $(n=3)$ relative to untreated control (medium only), whereas 4 days of FAC exposure caused no significant changes. B: After treatment for 16 hours with $3 \mathrm{nmol} / \mathrm{L}$ Bmp6, no change in Hepc1 mRNA was observed $(n=3)$. C: Treated cells had significantly higher levels of Id1. ${ }^{*} P<0.05$

tectable protein levels, whereas medium from treated cells had increased Bmp6 levels (data not shown). Consistent with in vivo experiments, in which neither intravitreal nor subretinal injection of Bmp6 up-regulated Hepc mRNA in the RPE, ARPE-19 cells showed no Hepc mRNA up-regulation after treatment with exogenous Bmp6 (Figure $6 \mathrm{~B})$. However, this treatment did activate Bmp6 signaling, as demonstrated by Id1 up-regulation (Figure 6C).

\section{Bmp6 Is Down-Regulated by Oxidative Stress}

Because oxidative stress plays a role in the pathogenesis of AMD, we tested whether oxidative stress can affect Bmp6 mRNA levels both in vitro and in vivo. First, conflu- ent ARPE-19 cells were exposed to a sublethal dose of $\mathrm{H}_{2} \mathrm{O}_{2}$. To verify that oxidative stress occurred, we tested mRNA levels of heme oxygenase 1 (Hmox1), an antioxidant enzyme whose promoter contains an antioxidant response element. ${ }^{50}$ After the treatment, Hmox 1 mRNA levels significantly increased (Figure 7A), whereas Bmp6 mRNA was significantly reduced, relative to untreated controls (Figure 7B).

Light is a major source of oxidative stress in the retina. To assess the affect of oxidative stress on Bmp6 expression in vivo, we exposed albino BALB/c mice to bright, cool white fluorescent light for 18 hours, using a protocol we had previously found to induce photo-oxidative stress $^{51}$ and cause the death of photoreceptors but not RPE within a week after the light exposure. ${ }^{41}$ Consistent with their exposure to oxidative stress, RPE cells isolated from these mice a few hours after light exposure significantly up-regulated Hmox1 mRNA levels relative to the control group (Figure 7C), whereas, consistent with the in vitro experiment, Bmp6 mRNA was significantly downregulated (Figure $7 \mathrm{D}$ ).

\section{Bmp6 Levels Are Altered in Age-Related Macular Degeneration}

To determine whether Bmp6 may play a role in the iron accumulation previously observed within the RPE and photoreceptors in AMD retinas, Bmp6 protein levels were compared in postmortem AMD eyes with eyes from agematched controls. In early $A M D$ retina sections, some RPE cells had decreased Bmp6 immunolabel, compared with neighboring RPE cells and age-matched normal cells (Figure 8A, upper right). In contrast, advanced AMD eyes with either geographic atrophy or neovascularization had increased Bmp6 immunolabel within the neurosensory retina (Figure 8A, lower right panel), but the RPE had degenerated. This is consistent with increased Bmp6
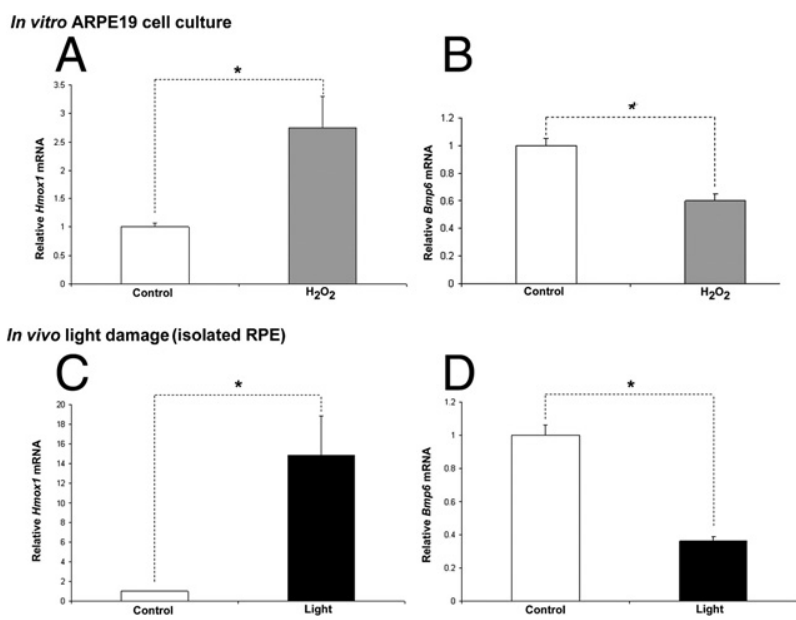

Figure 7. Effect of oxidative stress in cultured cells and in mice on Bmp6 and Hmox1 mRNAs assessed by real-time PCR. At 16 hours of treatment of ARPE-19 cells with $75 \mu \mathrm{mol} / \mathrm{L} \mathrm{H}_{2} \mathrm{O}_{2}$, Hmox1 was significantly up-regulated (A), but Bmp6 mRNA was significantly down-regulated $(\mathbf{B})$, relative to untreated controls (with MEM only; $n=6$ ). After photic injury, Hmox1 mRNA levels were significantly increased within isolated RPE (C), whereas Bmp6 mRNA levels were significantly decreased (D) compared with control. ${ }^{*} P<0.05$. 
A
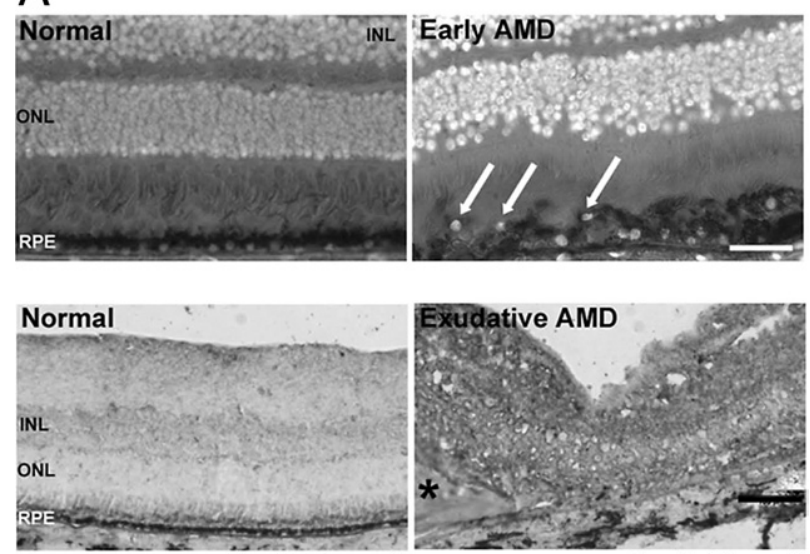

Anti Bmp6

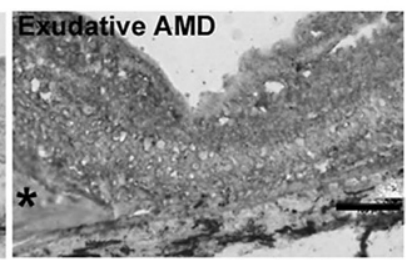

Anti Bmp6

\section{B Neurosensory retina}



$\mathrm{D}$

\section{$\mathrm{H}_{2} \mathrm{O}_{2} \longrightarrow \mid \mathrm{Bmp} 6 \longrightarrow \boldsymbol{\uparrow}^{\mathrm{Fe}} \longrightarrow \boldsymbol{\uparrow}^{\mathrm{Bmp} 6}$}

Figure 8. Bmp6 protein levels in age-related macular degeneration. A Bright-field photomicrographs of postmortem human retinas showed weaker Bmp6 immunoreactivity (black labeling) within RPE in early AMD (upper right, arrows), relative to normal human RPE (upper left). In advanced AMD, relative to normal, the signal was stronger throughout the neurosensory retina (lower right); the asterisk indicates subretinal fibrous scar. The RPE is absent, as it had degenerated. Nuclei, visualized with DAPI stain and simultaneous fluorescence imaging, appear white. B: Western analysis from four normal and four AMD neurosensory retinas showed significantly higher Bmp6 precursor protein levels $(57 \mathrm{kDa})$ in AMD eyes relative to normal controls. C: Densitometry confirmed the Western blot analysis. D: A model for the relationships among iron, oxidative stress, and Bmp6. F, female; $\mathrm{M}$, male; MW, molecular weight ladder. ${ }^{*} P<0.05$. Scale bars: $50 \mu \mathrm{m}(\mathbf{A}$, upper row); $100 \mu \mathrm{m}$ (A, lower row)

protein levels detected by Western blot analysis in advanced $A M D$ neurosensory retina extracts, relative to age-matched controls (Figure 8, B and C).

\section{Discussion}

The peptide hormone hepcidin is a central regulator of systemic iron homeostasis ${ }^{52}$ and plays an important local role in retinal iron regulation. ${ }^{17}$ Recent reports suggest that normal Hepc expression requires Bmp6 signaling. ${ }^{21-23}$ Our results indicate that Bmp6 regulates retinal iron. We demonstrate that Bmp6 is expressed in the RPE and its receptors are expressed in the neurosensory retina. Bmp6 levels can be regulated by iron, because exogenous iron administration up-regulated Bmp6 mRNA and induced Bmp6 secretion in cultured RPE cells (Figure 6). Bmp6 secreted from the RPE cells likely binds Bmp6 receptors in the neurosensory retina up-regulating Hepc, because both intravitreal and subretinal injection of Bmp6 up-regulated Hepc within the neurosensory retina but not within the RPE. Within the neurosensory retina, Müller glia are likely the cells that respond to the Bmp6 secreted by the RPE. Cultured Müller glia upregulated Hepc after addition of Bmp6 protein. Bmp6mediated Hepc up-regulation in the neurosensory retina changed labile iron levels in both the neurosensory retina and the RPE. Bmp6 is important for retinal health. The $B m p 6^{-1-}$ mice had age-dependent iron accumulation followed by severe retinal degeneration, and postmortem AMD retinas had altered Bmp6 levels. Oxidative stress down-regulated Bmp6 in RPE cells in culture and in mice, suggesting a mechanism for Bmp6 dysregulation in AMD.

Male $B m p 6^{-1-}$ mice exhibited retinal iron accumulation and severe retinal degeneration. The degeneration was not present at 7 weeks, but was extensive at 41 weeks, indicating that this is an age-related and not a developmental phenotype. The degeneration consisted of photoreceptor death and RPE hypertrophy with RPE autofluorescence (Figure 1). The RPE autofluorescence spectral analysis suggests that iron-induced oxidative damage in the male $B m p 6^{-1-}$ mice results in accumulation of molecules that are likely present in the RPE in AMD (Figure 1), given that hypertrophic RPE cells from $\mathrm{Bmp6}^{-/-}$mice and RPE cells in the postmortem eye of a patient with AMD had several similar emission peaks (Figure 1).

Male $B m p 6^{-1-}$ mice had elevated iron levels in the retinal neurons and in the RPE. Although the amount of iron in the neurosensory retina was below the sensitivity for Perls' staining, an increase in neurosensory retinal iron was detectable by BPS (Figure 2) and indirectly by elevated ferritin and decreased TfR protein levels (Figure 2). High iron levels within RPE were detectable by both Perls' stain and BPS (Figure 2). Female mutant mice accumulated iron in neither the retina nor RPE/choroid and had morphologically normal retinas. Further studies in female wild-type and $B m p 6^{-1-}$ mice are required to elucidate reasons for this difference, which might be due to hormonal influences on iron regulation or to compensatory iron regulatory pathways present only in females. There was no difference in Bmp6 expression within the RPE of male versus female wild-type mice (data not shown). There was also no sex-related difference in the mRNA levels of bone morphogenetic proteins 2, 4, 7, and 9 in the RPE (data not shown). Also, because bone morphogenetic proteins are members of the tumor growth factor $\beta$ superfamily, sex-related differences in the function of 
any of these family members might account for our observations.

To explore potential Bmp6 signaling pathways within the retina, we localized retinal Bmp6 and Bmp receptors. Bmp6 localized to the apical side of the RPE in both mouse and human retinas (Figure 3). Isolated mouse RPE cells exhibited significantly higher Bmp6 message levels relative to neurosensory retina. In contrast, the mRNA levels of the Bmp receptors Acvr1 and Bmpr2 were significantly higher in the neurosensory retina relative to the RPE. These results suggest that the RPE is the primary site of Bmp6 production and that the neurosensory retina is the target tissue for RPE-produced Bmp6. This is consistent with expression by the neurosensory retina of Hepc, the downstream effector of Bmp6 signaling. Intravitreal and subretinal Bmp6 injections significantly upregulated Hepc mRNA levels in neurosensory retina (Figure 4), but not RPE/choroid, suggesting that the neurosensory retina is the primary site of Bmp6-induced Hepc production. Intraocular Bmp6 injection also caused Hepc-dependent changes in labile iron, as indicated by down-regulation of Tfrc in the neurosensory retina and up-regulation of Tfrc in the RPE. This finding suggests that acute Hepc production by the neurosensory retina may trap iron in the neurosensory retina while diminishing iron transfer from neurosensory retina to RPE. To identify cells within the neurosensory retina that up-regulate Hepc in response to Bmp6, we cultured primary mouse Müller cells and found that Bmp6 increased the mRNAs of both Hepc and Id1 (Figure 4).

To test environmental regulators of Bmp6 expression, we treated cultured, immortal human RPE cells (ARPE19) with iron and found significant Bmp6 mRNA up-regulation (Figure 6), suggesting that Bmp6 may be produced to limit further iron export from neighboring cells in the neurosensory retina. Longer iron exposure did not up-regulate Bmp6, suggesting that primarily acute increases in iron levels up-regulate Bmp6 in these cells. Consistent with the intraocular Bmp6 injections in mice, treatment of ARPE-19 cells with exogenous Bmp6 failed to up-regulate Hepc mRNA (Figure 6), although Bmp6 signaling pathways were activated, as indicated by almost fivefold up-regulation of Id1 mRNA.

Because in AMD the eyes accumulate iron in the RPE and photoreceptors, ${ }^{53}$ and because the above data suggest that Bmp6 is an important regulator of retinal iron homeostasis, we assessed Bmp6 levels in postmortem AMD retinas, compared with age-matched controls. In early AMD, diminished Bmp6 levels were found in RPE cells overlying drusen, the sub-RPE deposits characteristic of AMD (Figure 8). Diminished Bmp6 expression might be caused by the oxidative stress that has been associated with $A M D,{ }^{34,36,54}$ given that oxidative stress diminishes Bmp6 mRNA levels in cultured RPE cells (Figure 7). Lower Bmp6 levels could permit increased iron uptake into the neurosensory retina from retinal vasculature through Fpn, which localizes to the vascular endothelium and exports iron from the abluminal side of these cells. ${ }^{17}$ This could lead to retinal iron accumulation, as occurs in Bmp6 ${ }^{-/-}$mice. In advanced AMD, Bmp6 levels increase in the neurosensory retina, potentially induced by elevated iron levels (Figure 8). A model (Figure 8D) indicates that $\mathrm{Bmp} 6$ is down-regulated by oxidative stress, as shown in our light damage and ARPE- $19 \mathrm{H}_{2} \mathrm{O}_{2}$ experiments. On the other hand, BMP6 is up-regulated by iron, as indicated by FAC exposure of ARPE- 19 cells. Our observation of decreased Bmp6 in early AMD and increased Bmp6 in late AMD suggests that oxidative stress may down-regulate Bmp6 in early AMD, contributing to retinal iron accumulation (similar to $\mathrm{Bmp6}^{-\mathrm{I}^{-}}$ mice), followed by Bmp6 up-regulation by iron in the neurosensory retina in advanced AMD. The mechanism of Bmp6 up-regulation by iron is a topic for future investigation; our data suggest that it does not involve ironinduced oxidative stress.

Our results suggest that Bmp6 is important for retinal iron regulation and retinal health. Acute increases in RPE iron caused increased Bmp6 production. Once secreted from the RPE cells, Bmp6 is likely to bind its receptors, which we show are present in the neurosensory retina, up-regulating Hepc (as occurred with intravitreal or subretinal injection of exogenous Bmp6). The increase in Hepc would trigger Fpn degradation, limiting both retinal iron import through vascular endothelial cells ${ }^{17}$ and iron export from Fpn-expressing cells in the neurosensory retina, including the Müller glia. Decreased Tfrc mRNA in the neurosensory retina after Bmp6 injection into retinas of $116^{-1-}$ but not $\mathrm{Hepc1}^{-1-}$ mice suggests that an acute increase in Bmp6 in the neurosensory retina can cause a Hepc-mediated increase in intracellular labile iron in the neurosensory retina. Thus, the iron-loaded RPE may communicate its iron supply to the neurosensory retina through Bmp6, limiting retinal iron uptake through vascular endothelial cells and promoting iron storage within Müller cells and vascular endothelial cells, as opposed to transfer to retinal neurons. Oxidative stress-induced Bmp6 down-regulation in cultured RPE cells and in some RPE cells overlying drusen suggests that Bmp6 dysregulation, caused by oxidative stress, could contribute to inappropriate iron transport and retinal iron accumulation. In the RPE (as well as in other Bmp6-expressing organs, including liver and brain), this might lead to a vicious cycle of iron-induced oxidative stress followed by more iron accumulation, with eventual activation of senescence, apoptosis, or angiogenesis pathways.

\section{Acknowledgments}

We thank Christine Curcio (University of Alabama) for frozen human retinas and Ray Meade and Xinyu (Jasmine) Zhao (University of Pennsylvania Biomedical Imaging Core) for research support.

\section{References}

1. Lee DW, Andersen JK: Iron elevations in the aging Parkinsonian brain: a consequence of impaired iron homeostasis? J Neurochem 2010, 112:332-339

2. Snyder AM, Connor JR: Iron, the substantia nigra and related neurological disorders. Biochim Biophys Acta 2009, 1790:606-614

3. Smith MA, Zhu X, Tabaton M, Liu G, McKeel DW Jr, Cohen ML, Wang $X$, Siedlak SL, Dwyer BE, Hayashi T, Nakamura M, Nunomura A, Perry 
G: Increased iron and free radical generation in preclinical Alzheimer disease and mild cognitive impairment. J Alzheimers Dis 2010 , 19:363-372

4. Hahn P, Ying GS, Beard J, Dunaief JL: Iron levels in human retina: sex difference and increase with age. Neuroreport 2006, 17:1803-1806

5. Weinberg ED: Iron out-of-balance: a risk factor for acute and chronic diseases. Hemoglobin 2008, 32:117-122

6. Zacharski LR, Chow BK, Howes PS, Shamayeva G, Baron JA, Dalman $\mathrm{RL}$, Malenka DJ, Ozaki CK, Lavori PW: Decreased cancer risk after iron reduction in patients with peripheral arterial disease: results from a randomized trial. J Natl Cancer Inst 2008, 100:996-1002

7. Zecca L, Youdim MB, Riederer P, Connor JR, Crichton RR: Iron, brain ageing and neurodegenerative disorders. Nat Rev Neurosci 2004, 5:863-873

8. Gitlin JD: Aceruloplasminemia. Pediatr Res 1998, 44:271-276

9. Miyajima H, Kono S, Takahashi Y, Sugimoto M: Increased lipid peroxidation and mitochondrial dysfunction in aceruloplasminemia brains. Blood Cells Mol Dis 2002, 29:433-438

10. Dunaief JL, Richa C, Franks EP, Schultze RL, Aleman TS, Schenck JF Zimmerman EA, Brooks DG: Macular degeneration in a patient with aceruloplasminemia, a disease associated with retinal iron overload. Ophthalmology 2005, 112:1062-1065

11. Bird AC: Therapeutic targets in age-related macular disease. J Clin Invest 2010, 120:3033-3041

12. Dunaief JL: Iron induced oxidative damage as a potential factor in age-related macular degeneration: the Cogan Lecture. Invest Ophthalmol Vis Sci 2006, 47:4660-4664

13. Gnana-Prakasam JP, Martin PM, Smith SB, Ganapathy V: Expression and function of iron-regulatory proteins in retina. IUBMB Life 2010 , 62:363-370

14. Hahn P, Qian Y, Dentchev T, Chen L, Beard J, Harris ZL, Dunaief JL: Disruption of ceruloplasmin and hephaestin in mice causes retinal iron overload and retinal degeneration with features of age-related macular degeneration. Proc Natl Acad Sci USA 2004, 101:1385013855

15. Hadziahmetovic M, Dentchev T, Song Y, Haddad N, He X, Hahn P, Pratico D, Wen R, Harris ZL, Lambris JD, Beard J, Dunaief JL: Ceruloplasmin/hephaestin knockout mice model morphologic and molecular features of AMD. Invest Ophthalmol Vis Sci 2008, 49:27282736

16. Hadziahmetovic M, Song Y, Wolkow N, lacovelli J, Grieco S, Lee J, Lyubarsky A, Pratico D, Connelly J, Spino M, Harris ZL, Dunaief J: The oral iron chelator deferiprone protects against iron overload-induced retinal degeneration. Invest Ophthalmol Vis Sci 2010, 52:959-968

17. Hadziahmetovic M, Song Y, Ponnuru P, lacovelli J, Hunter A, Haddad $\mathrm{N}$, Beard J, Connor JR, Vaulont S, Dunaief J: Age-dependent retinal iron accumulation and degeneration in hepcidin knockout mice. Invest Ophthalmol Vis Sci 2010, 52:109-119

18. Nemeth E, Tuttle MS, Powelson J, Vaughn MB, Donovan A, Ward DM, Ganz T, Kaplan J: Hepcidin regulates cellular iron efflux by binding to ferroportin and inducing its internalization. Science 2004, 306:20902093

19. Gnana-Prakasam JP, Martin PM, Mysona BA, Roon P, Smith SB, Ganapathy $\mathrm{V}$ : Hepcidin expression in mouse retina and its regulation via lipopolysaccharide/Toll-like receptor-4 pathway independent of Hfe. Biochem J 2008, 411:79-88

20. Hahn P, Dentchev T, Qian Y, Rouault T, Harris ZL, Dunaief JL: Immunolocalization and regulation of iron handling proteins ferritin and ferroportin in the retina. Mol Vis 2004, 10:598-607

21. Babitt JL, Huang FW, Wrighting DM, Xia Y, Sidis Y, Samad TA, Campagna JA, Chung RT, Schneyer AL, Woolf CJ, Andrews NC, Lin $\mathrm{HY}$ : Bone morphogenetic protein signaling by hemojuvelin regulates hepcidin expression. Nat Genet 2006, 38:531-539

22. Andriopoulos B Jr, Corradini E, Xia Y, Faasse SA, Chen S, Grgurevic L, Knutson MD, Pietrangelo A, Vukicevic S, Lin HY, Babitt JL: BMP6 is a key endogenous regulator of hepcidin expression and iron metabolism. Nat Genet 2009, 41:482-487

23. Kautz L, Meynard D, Monnier A, Darnaud V, Bouvet R, Wang RH, Deng C, Vaulont S, Mosser J, Coppin H, Roth MP: Iron regulates phosphorylation of Smad1/5/8 and gene expression of Bmp6, Smad7, Id1, and Atoh8 in the mouse liver. Blood 2008, 112:15031509

24. Shi Y, Massagué J: Mechanisms of TGF-beta signaling from cell membrane to the nucleus. Cell 2003, 113:685-700
25. Meynard D, Kautz L, Darnaud V, Canonne-Hergaux F, Coppin H, Roth MP: Lack of the bone morphogenetic protein BMP6 induces massive iron overload. Nat Genet 2009, 41:478-481

26. Lavery K, Swain P, Falb D, Alaoui-Ismaili MH: BMP-2/4 and BMP-6/7 differentially utilize cell surface receptors to induce osteoblastic differentiation of human bone marrow-derived mesenchymal stem cells. J Biol Chem 2008, 283:20948-20958

27. Reddi H: Bone morphogenetic proteins. Adv Dent Res 1995, 9(3 Suppl): 13

28. Celeste AJ, Iannazzi JA, Taylor RC, Hewick RM, Rosen V, Wang EA Wozney JM: Identification of transforming growth factor beta family members present in bone-inductive protein purified from bovine bone. Proc Natl Acad Sci USA 1990, 87:9843-9847

29. Cunningham NS, Jenkins NA, Gilbert DJ, Copeland NG, Reddi AH, Lee SJ: Growth/differentiation factor-10: a new member of the transforming growth factor-beta superfamily related to bone morphogenetic protein-3. Growth Factors 1995, 12:99-109

30. Sikder HA, Devlin MK, Dunlap S, Ryu B, Alani RM: Id proteins in cell growth and tumorigenesis. Cancer Cell 2003, 3:525-530

31. Trousse F, Esteve P, Bovolenta P: Bmp4 mediates apoptotic cell death in the developing chick eye. J Neurosci 2001, 21:1292-1301

32. Belecky-Adams TL, Adler R, Beebe DC: Bone morphogenetic protein signaling and the initiation of lens fiber cell differentiation. Development 2002, 129:3795-3802

33. Zhu D, Wu J, Spee C, Ryan SJ, Hinton DR: BMP4 mediates oxidative stress-induced retinal pigment epithelial cell senescence and is overexpressed in age-related macular degeneration. J Biol Chem 2009 284:9529-9539

34. Zarbin MA: Current concepts in the pathogenesis of age-related macular degeneration. Arch Ophthalmol 2004, 122:598-614

35. Shen JK, Dong A, Hackett SF, Bell WR, Green WR, Campochiaro PA: Oxidative damage in age-related macular degeneration. Histol Histopathol 2007, 22:1301-1308

36. Hollyfield JG, Bonilha VL, Rayborn ME, Yang X, Shadrach KG, Lu L, Ufret RL, Salomon RG, Perez VL: Oxidative damage-induced inflammation initiates age-related macular degeneration. Nat Med 2008 , 14:194-198

37. Solloway MJ, Dudley AT, Bikoff EK, Lyons KM, Hogan BL, Robertson EJ: Mice lacking Bmp6 function. Dev Genet 1998, 22:321-339

38. Lesbordes-Brion JC, Viatte L, Bennoun M, Lou DQ, Ramey G, Houbron C, Hamard G, Kahn A, Vaulont S: Targeted disruption of the hepcidin 1 gene results in severe hemochromatosis. Blood 2006, 108:1402-1405

39. Torrance JD, Bothwell TH: A simple technique for measuring storage iron concentrations in formalinised liver samples. S Afr J Med Sci 1968, 33:9-11

40. Dunaief JL, Dentchev T, Ying G-S, Milam AH: The role of apoptosis in age-related macular degeneration. Arch Ophthalmol 2002, 120: 1435-1442

41. Chen L, Wu W, Dentchev T, Zeng Y, Wang J, Tsui I, Tobias JW, Bennett J, Baldwin D, Dunaief JL: Light damage induced changes in mouse retinal gene expression. Exp Eye Res 2004, 79:239-247

42. Hicks D, Courtois Y: The growth and behaviour of rat retinal Müller cells in vitro. 1. An improved method for isolation and culture. Exp Eye Res 1990, 51:119-129

43. Schmitz-Valckenberg S, Fleckenstein M, Scholl HP, Holz FG: Fundus autofluorescence and progression of age-related macular degeneration. Surv Ophthalmol 2009, 54:96-117

44. Zhou J, Kim SR, Westlund BS, Sparrow JR: Complement activation by bisretinoid constituents of RPE lipofuscin. Invest Ophthalmol Vis Sci 2009, 50:1392-1399

45. Rouault TA, Hentze MW, Caughman SW, Harford JB, Klausner RD: Binding of a cytosolic protein to the iron-responsive element of human ferritin messenger RNA. Science 1988, 241:1207-1210

46. Rouault T, Klausner R: Regulation of iron metabolism in eukaryotes Curr Top Cell Regul 1997, 35:1-19

47. Muckenthaler MU, Galy B, Hentze MW: Systemic iron homeostasis and the iron-responsive element/iron-regulatory protein (IRE/IRP) regulatory network. Annu Rev Nutr 2008, 28:197-213

48. Corradini E, Garuti C, Montosi G, Ventura P, Andriopoulos B Jr, Lin $\mathrm{HY}$, Pietrangelo A, Babitt JL: Bone morphogenetic protein signaling is impaired in an HFE knockout mouse model of hemochromatosis. Gastroenterology 2009, 137:1489-1497 
49. Kautz L, Meynard D, Besson-Fournier C, Darnaud V, Al Saati T, Coppin H, Roth MP: BMP/Smad signaling is not enhanced in Hfedeficient mice despite increased Bmp6 expression. Blood 2009, 114 2515-2520

50. Alam J, Stewart D, Touchard C, Boinapally S, Choi AM, Cook JL: Nrf2, a Cap'n'Collar transcription factor, regulates induction of the heme oxygenase-1 gene. J Biol Chem 1999, 274:26071-26078

51. Dentchev T, Yao Y, Pratico D, Dunaief J: Isoprostane F2alpha-VI, a new marker of oxidative stress, increases following light damage to the mouse retina. Mol Vis 2007, 13:190-195
52. Viatte L, Vaulont S: Hepcidin, the iron watcher. Biochimie 2009 , 91:1223-1228

53. Hahn P, Milam AH, Dunaief JL: Maculas affected by age-related macular degeneration contain increased chelatable iron in the retinal pigment epithelium and Bruch's membrane. Arch Ophthalmol 2003 121:1099-1105

54. Shen J, Xie B, Dong A, Swaim M, Hackett SF, Campochiaro PA: In vivo immunostaining demonstrates macrophages associate with growing and regressing vessels. Invest Ophthalmol Vis Sci 2007 48:4335-4341 